\title{
Cardiovascular Risk in Patients with Subclinical Hypothyroidism
}

\author{
Leonidas H Duntas ${ }^{1}$ and Luca Chiovato²
}

1. Professor, Unit of Endocrinology, Metabolism and Diabetes, Evgenidion Hospital, University of Athens, Greece;

2. Professor, Unit of Internal Medicine and Endocrinology, Fondazione Salvatore Maugeri Istituto di Ricovero e Cura a Carattere Scientifico, University of Pavia, Italy

\begin{abstract}
Subclinical hypothyroidism (SCH) has been associated with increased cardiovascular mortality due to adverse effects mainly on lipids and blood pressure (BP). There is evidence that $\mathrm{SCH}$, especially in patients with thyroid-stimulating hormone (TSH) $>10 \mathrm{mU} / \mathrm{I}$, may increase cardiovascular risk. Some uncertainty exists regarding the association of $\mathrm{SCH}$ with BP; however, that the coexistence of $\mathrm{SCH}$ with $\mathrm{BP}$ and hypercholesterolaemia has a negative cardiovascular impact is beyond doubt. Insulin resistance, by modulating various risk factors including coagulation, may potentially increase cardiovascular risk. Periodic health examinations including screening has been advised in patients $>35$ years of age, while treatment with thyroxine should be tailored to each patient.
\end{abstract}

\section{Keywords}

Subclinical hypothyroidism, cardiovascular risk, thyroid-stimulating hormone, lipids, blood pressure, the metabolic syndrome

Disclosure: Leonidas H Duntas and Luca Chiovato have no conflicts of interest to declare. No funding was received for the publication of this article. Received: 11 June 2014 Accepted: 4 August 2014 Citation: European Endocrinology, 2014;10(2):157-60 DOl:10.17925/EE.2014.10.02.157

Correspondence: Leonidas H Duntas, Unit of Endocrinology, Metabolism and Diabetes, Evgenidion Hospital, University of Athens, 20 Papadiamantopoulou Street, 11520 Athens, Greece. E: ledunt@otenet.gr

Hypothyroidism is usually a progressive disease that impacts the entirety of bodily functions. As the heart is the main target of thyroid hormone activity, hypothyroidism may precipitate or aggravate heart failure, influencing heart rate and blood pressure (BP) while increasing cardiovascular (CV) stiffness and also cardiomegaly. ${ }^{1,2}$ Overt hypothyroidism $(\mathrm{OH})$ is therefore associated with heightened CV morbidity and mortality. ${ }^{3}$ Subclinical hypothyroidism $(\mathrm{SCH})$ is defined as a condition characterised by elevated serum thyroid-stimulating hormone (TSH) concentrations (TSH: $>4.5 \mathrm{mu} / \mathrm{l}$ ), while circulating thyroxine (T4) and tri-iodothyronine (T3) levels remain within the population reference range. ${ }^{4}$ The incidence of $\mathrm{SCH}$ varies between 4 and $20 \%$ depending upon the gender (females are more prone), age (older than 65) and population studied. 5.6

The consequences of $\mathrm{SCH}$ are variable at several levels and may depend on the duration and the degree of elevation of serum TSH. Hence, a number of important questions arise relating to $\mathrm{SCH}$, including whether it raises $\mathrm{CV}$ risk and therefore mortality, whether it negatively influences metabolic parameters and whether it should be treated with L-thyroxine. ${ }^{4,7}$

Besides the classic risk factors for CV disease (CVD), i.e. hypercholesterolaemia and diastolic hypertension, some newer risk factors such as a disrupted coagulability and insulin resistance have recently been evaluated. ${ }^{8}$ This review aims to update and discuss the available data regarding $\mathrm{CV}$ risk in patients with $\mathrm{SCH}$.

\section{Subclinical Hypothyroidism and Lipids}

Clinical hypothyroidism has been associated with elevated levels of total cholesterol (TC), low-density lipoprotein cholesterol (LDL-C) and apolipoprotein $\mathrm{B}$ (ApoB), all of which contribute substantially to heightened risk of coronary artery disease. ${ }^{9-11}$ Thyroid hormone controls the generation of cholesterol by regulating the activity of the 3-hydroxy- 3-methylglutaryl-coenzyme A (HMG-COA) enzyme and its degradation rate by regulating the expression of the SREBP-2 gene, the transcription factor that positively regulates the activity of LDL receptor. ${ }^{12,13}$ Thus, thyroid hormone action on lipids mainly occurs through an increased expression of LDL receptors at the hepatic and peripheral levels and via an increased activity of the enzymes involved in the metabolism of lipoproteins and reverse cholesterol transport, such as hepatic lipase $(\mathrm{HL})$, lipoprotein lipase $(\mathrm{LPL})$, cholesterol ester transport protein (CETP) and lecithin-cholesterol acyltransferase LCAT.14,15 However, these effects are dependent on the efficiency of thyroid function and/ or the degree of thyroid dysfunction. Changes in $\mathrm{HL}$ activity seem to modify cholesterol metabolism in thyroid dysfunction, while the thyroid hormone influence on LPL would appear to be of importance mainly in the disruption of triglyceride (TG) metabolism. ${ }^{15}$

Several studies have reported increased lipid levels in SCH depending on the degree of hypothyroidism, ${ }^{16,17}$ though a TSH threshold has not as yet been established. ${ }^{8}$ In the 5th Troms $\varnothing$ study, a cross-sectional epidemiological, nested case-control study including 5,143 subjects, a significant and positive correlation between serum TSH levels and serum TC and LDL-C levels was registered in both genders. ${ }^{19}$ Accordingly, patients with newly diagnosed SCH exhibited a significant rise in TGS and LDL-C and low HDLcholesterol compared with the control group after adjustment for age and body mass index (BMI) ${ }^{20}$ Importantly, women with TSH levels higher than $10 \mathrm{mIU} / \mathrm{l}$ exhibited a significant increase in small dense LDL particles, which are associated with a higher atherogenic index ${ }^{20}$ On the other hand, an association between free thyroxine (FT4) levels within the normal reference range and lipids, besides the association between SCH and hyperlipidaemia, has been demonstrated, ${ }^{21}$ while, in addition, low normal FT4 levels were significantly associated with increased insulin resistance, suggesting an increased CV risk in subjects with low normal thyroid function. 


\section{Figure 1: Hypothetical Dynamic of Thyroid- stimulating Hormone and Mortality Curve in Relation to Age}

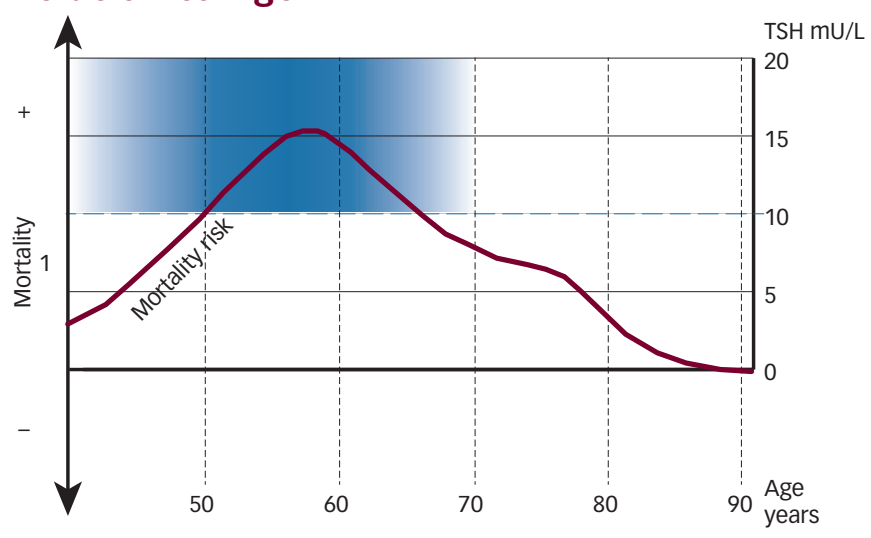

The peak of the mortality curve as regards thyroid-stimulating hormone (TSH) level is reached at around the age of 60 years.

In another recent study investigating whether $\mathrm{SCH}$ is associated with alterations in hepatic very-low-density lipoprotein (VLDL) metabolism, SCH was found to influence hepatic VLDL-TG but not VLDL-apoB-100 metabolism. ${ }^{22}$ It is thus evident that $\mathrm{SCH}$ increases the hepatic VLDLTG secretion rate compared with the euthyroid state. Moreover, the plasma VLDL-TG concentration was higher in $\mathrm{SCH}$ than in euthyroid controls due to greater release of large TG-rich VLDL particles from the liver. Recently it was shown that elevated serum levels of ApoB48 , a constituent of chylomicrons and chylomicron remnants and a suspected risk factor for atherosclerosis found in both $\mathrm{OH}$ and $\mathrm{SCH}$ patients, could possibly be reduced by L-T4 replacement. ${ }^{23}$ it has been hypothesised that these increased serum levels of ApoB-48 in patients with $\mathrm{OH}$ and $\mathrm{SCH}$ may be related to the disturbed metabolism of chylomicron remnants in patients with hypothyroidism. In the intervention arm of the same study (32 subjects administered T4; 32 subjects placebo), a significant reduction was observed in ApoB levels after T4 medication. Of note, the Tromsø study also revealed that T4 treatment led to lipid reduction in patients with $\mathrm{SCH}$. By contrast, the majority of randomised controlled studies did not reveal any reduction of TC and LDL-C with LT4. ${ }^{7}$ Most notably, no significant effects were seen in patients with baseline TC and LDL-C values that were below $260 \mathrm{mg} / \mathrm{dl}$ and $154 \mathrm{mg} / \mathrm{dl}$, respectively, and no difference was found compared with controls. ${ }^{24}$

Age is an important factor, particularly when treatment is considered. $\mathrm{SCH}$ may exert protective effects in the elderly, inducing a lower metabolic rate and reduced adrenergic tone. Moreover, very elderly patients (i.e. above 85 years of age) exhibit some important biological differences from moderately old patients (i.e. 60-70 years), since TC and $L D L-C$ are not considered to be independent $C V$ risk factors in the very old as they are in the middle aged. ${ }^{7,25}$ Therefore, while by boosting TSH the $\mathrm{CV}$ risk is increased in patients with $\mathrm{SCH}<65$ years thereby negatively affecting mortality, a protective mechanism can be observed in patients with $\mathrm{SCH}$ who are above 85 years old. Hypothetically, the mortality curve increases in younger $\mathrm{SCH}$ patients, i.e. up to the age of 65 years, and thereafter gradually decreases into very old age (see Figure 1). ${ }^{7,26}$

Recently, in a cross-sectional and controlled study including 49 children with persistent, idiopathic, long-standing ( $3.2 \pm 0.4$ years), mild $\mathrm{SCH}$ (TSH: 4.5-10 mU/l), waist-to-height-ratio (WHtR) $(p<0.0001)$, atherogenic index ( $p=0.001)$, TGs/high-density (HDL)-cholesterol ratio $(p=0.01)$ and homocysteine levels $(p=0.002)$ were significantly higher and HDLcholesterol significantly lower ( $\mathrm{p}=0.003$ ) in $\mathrm{SCH}$ subjects compared with 49 controls. ${ }^{27}$ Following adjustment for $\mathrm{BMI}$, these variables remained significantly associated with the TSH levels or with $\mathrm{SCH}$ duration. indicating that even mild, long-lasting, untreated SCH may be associated with various pro-atherogenic abnormalities.

\section{Subclinical Hypothyroidism and Arterial Hypertension}

Though as yet a controversial matter, an association has been hypothesised between $\mathrm{SCH}$ and BP. Thus, in a cross-sectional study conducted among 6,992 inhabitants from six districts of Jiangsu province in China, $\mathrm{SCH}$ was not associated with $\mathrm{BP}$ and $\mathrm{SCH}$ did not independently predict increased relative risk (RR). ${ }^{28}$ In the Busselton study, neither mean systolic BP (SBP) and diastolic BP (DBP) nor the prevalence of hypertension differed significantly between $\mathrm{SCH}$ patients and controls. ${ }^{29}$ By contrast, as shown in the Hunt study examining 9,709 women and 4,644 men without previous thyroid disease, high normal TSH levels were associated with modestly higher future levels of $\mathrm{BP}$, this implying that TSH levels may co-vary with BP among people with apparently normal thyroid function. ${ }^{30}$

In a meta-analysis on the relationship between $\mathrm{SCH}$ and $\mathrm{SBP}, \mathrm{SCH}$ was associated with an elevated SBP and it was therefore hypothesised that it might serve as a potential risk factor for high SBP. ${ }^{31}$ Undoubtedly, welldesigned and large sample-sized prospective studies are needed to confirm the association between SCH and BP to determine whether treatment with $\mathrm{T} 4$ may be beneficial for $\mathrm{BP}$.

Hypothyroidism has been associated with arterial stiffness and left ventricular diastolic dysfunction. ${ }^{32,33}$ In a cross-sectional study investigating the relationship between thyroid hormone level and cardio-ankle vascular index (CAVI) and left ventricular diastolic function in 83 patients with untreated $\mathrm{SCH}$, log $\mathrm{N}$-terminal prohormone of brain natriuretic peptide (NT-proBNP), CAVI and C-reactive protein (CRP) were found higher in $\mathrm{SCH}^{34}$ Thus, high logNT-proBNP might be associated with a raised $\mathrm{CAVI}$ in patients with $\mathrm{SCH}$, this state possibly constituting a risk factor for $\mathrm{CV}$ events related to arterial stiffening and left ventricular diastolic dysfunction. ${ }^{34}$

Additionally, $\mathrm{SCH}$ may represent a risk factor for coronary artery calcification (CAC), especially in subjects with intermediate and high CV risk scores. ${ }^{35}$ Thus, CAC score (CACS) was found higher in $\mathrm{SCH}$ patients compared with controls ( $\mathrm{Cntr}$ versus $\mathrm{SCH} ; \mathrm{p}=0.045$ ). In a multivariate analysis, the risk for CACS $>100$ was independently associated with male gender, age $>55$ years and the presence of $\mathrm{SCH}$.

\section{Hypercoagulation and Insulin Resistance}

More recently, CRP, homocysteine, increased arterial stiffness, endothelial dysfunction and altered coagulation parameters have been implicated in $\mathrm{SCH}^{36}$ There have also been reports of abnormalities in glucose metabolism and in haemostatic parameters, the latter being mainly indicated by the increased activity of factor $\mathrm{VII}{ }^{37}$ and plasminogen activator inhibitor-1, suggesting that a hypofibrinolytic and hypercoagulable state may play a significant role in the development of atherosclerosis in patients with $\mathrm{SCH}^{38}$

A recent report in patients with a post-non-ST elevation acute coronary syndrome found a higher thrombus burden in the subclinically hypothyroid 
ones compared with euthyroid individuals, as evidenced by the area of the thrombus: mean 23,608 versus $16,661 \mu \mathrm{m}^{2} / \mathrm{mm}$ ( $\mathrm{p}=0.02$ ). ${ }^{39}$ However, this association was not detectable when the analysis was limited to patients with serum TSH within the reference range, since neither serum FT4 nor FT3 had any significant association with the thrombus area. ${ }^{39}$ Serum TSH levels, particularly in the SCH range, were associated with a higher thrombus burden despite optimal recommended secondary prevention therapy, this possibly accounting for the higher CV risk seen in $\mathrm{SCH}$ patients.

In a cross-sectional study including 753 subjects and investigating the role of intrahepatic fat accumulation in the association of $\mathrm{SCH}$ with insulin resistance, the prevalence of fatty liver (FL) was not different among euthyroid and $\mathrm{SCH}$ patients (31.8 versus $27.8 \%$; $\mathrm{p}=0.371$ ). ${ }^{40}$ However, the FL plus SCH subjects were heavier and exhibited more metabolic abnormalities compared with those with $\mathrm{SCH}$ and no FL. According to the authors, patients with $\mathrm{SCH}$ and $\mathrm{FL}$ have increased odds for insulin resistance, the metabolic syndrome and also CAC.

The association between $\mathrm{SCH}$ and weight changes in the elderly was the objective of a recent study examining a total of $427 \mathrm{SCH}$ patients $>65$ years old over a period of 6 years. ${ }^{41}$ Patients with $\mathrm{SCH}$ showed no fluctuations in weight at a single time point compared with euthyroid controls, nor were differences in lean mass or fat percent noted. It is of interest that a TSH level of $1 \mathrm{mU} / \mathrm{l}$ higher within the $\mathrm{SCH}$ or euthyroid range, as well as a $1 \mathrm{ng} / \mathrm{dl}$ higher FT4 level, were associated with a $0.5 \mathrm{~kg}$ higher baseline weight or lower baseline weight and $0.3 \mathrm{~kg} / \mathrm{year}$ greater weight loss in women, respectively. Though the association between $\mathrm{SCH}$ and weight is not at present well defined, these results indicate that $\mathrm{SCH}$ does not exert a significant impact on weight in the elderly. Nevertheless, there are still some limitations that should be considered, as normal values of TSH are not as yet clearly defined for every population: the upper limit is ageand race-related and it might also be dependent on occult autoimmune thyroiditis or inactivating polymorphisms of TSH receptor. ${ }^{4}$

\section{Subclinical Hypothyroidism and Mortality}

$\mathrm{SCH}$ has been associated with increased risk of $\mathrm{CHD}$, and several studies and meta-analyses have investigated the association of $\mathrm{SCH}$ with $\mathrm{CV}$ risk and mortality. 42,43 The aforementioned Busselton study, which was conducted in Australia to examine the prevalence of $\mathrm{CHD}$ in patients with and without $\mathrm{SCH}$, found a higher statistical significant in both the crosssectional and longitudinal analysis (age- and sex-adjusted hazard ratio [HR] 1.7; 95 \% confidence interval [Cl] 1.2-2.4; $\mathrm{p}<0.01$ ) in SCH patients compared with euthyroid controls. ${ }^{44}$ Importantly, the increased risk of CHD events remained significant after adjustment for standard CV risk factors. A high risk of coronary heart disease (CHD) events and mortality was reported in dependency on the degree of TSH, with lower risk of all-cause mortality in SCH patients having a TSH between 5-10 mU/l, and also in subjects younger than 65 years. ${ }^{45}$ According to another metaanalysis, $\mathrm{SCH}$ is associated with a significant risk of $\mathrm{CHD}$ at baseline (RR with $95 \% \mathrm{Cl} 1.533$ [1.312-1.791]; $\mathrm{p}<0.05$ ) and at follow-up (RR with $95 \%$ $\mathrm{Cl} 1.188$ [1.024-1.379]; $p<0.05$ ). ${ }^{46}$ The noted discrepancies among the various studies have been attributed to different study designs, degree of SCH and gender and age of the study populations. ${ }^{47}$

More recently, in a Taiwanese 10-year follow-up study including 11,574 participants without a history of thyroid disease in which $\mathrm{SCH}$ was defined as a serum TS level of 5.0-19.96 mU/l with normal TT4 concentrations, 680 out of 3,669 deaths were due to CVD. ${ }^{48}$ Compared with euthyroid subjects after adjustment for several confounders, the relative ratio of deaths from all causes and CVD among subjects with $\mathrm{SCH}$ was increased, indicating that Taiwanese with $\mathrm{SCH}$ have an increased risk for all-cause mortality and CVD death.

In a large prospective cohort study, 212,456 middle-aged euthyroid men and women, without a history of thyroid disease at baseline, were followed from 2002 to 2009. ${ }^{49}$ Serum concentrations of FT4 and FT3 within the normal range, were inversely associated with the risk of all-cause mortality and also cancer mortality, particularly liver cancer mortality, while TSH was not associated with mortality endpoints. ${ }^{49}$ By contrast, an analysis of data of 55,287 participants in 11 prospective cohort studies in the US, Europe, Australia, Brazil and Japan ${ }^{50}$ revealed an increased risk of CHD events and $\mathrm{CHD}$ mortality with increasing TSH concentrations above $10 \mathrm{mU} / .{ }^{50}$ The $\mathrm{SCH}$ was however defined as a TSH level from $4.5 \mathrm{mU} / \mathrm{l}$ to $19.9 \mathrm{mIU} / \mathrm{l}$ with normal serum $\mathrm{T} 4$ levels. Notably, the results were similar after adjustment for traditional $\mathrm{CV}$ risk factors and the risks were not significantly modified by age, sex or pre-existing CVD. The risk of all-cause mortality, major adverse CV events (MACEs) and cause-specific events in subjects with overt and subclinical dysfunction was investigated in a retrospective cohort study in Denmark. ${ }^{51}$ While the risk of MACEs was elevated in both overt and subclinical hyperthyroidism driven by heart failure, a reduction of all-cause mortality was registered in $\mathrm{SCH}$ with $\mathrm{TSH}$ of $5-10 \mathrm{mIU} / \mathrm{I}$ (Incidence rate ratio [IRR] 0.92, $95 \%$ Cl 0.86-0.98).

It has recently been reported that $\mathrm{CHD}$ risk associated with $\mathrm{SCH}$ is not modified by thyroid peroxidase antibody (TPOAb) status, suggesting that biomarkers of thyroid autoimmunity do not add independent prognostic information concerning CHD outcomes. ${ }^{52}$

\section{Treatment Options and Conclusions}

Despite the fact that LT4 treatment in SCH has resulted in an improvement of various $\mathrm{CV}$ risk factors and quality of life, ${ }^{53}$ there is no evidence that treatment is able to reverse $\mathrm{CV}$ lesions by decreasing $\mathrm{CV}$ risk, especially in those patients with $\mathrm{TSH}<10 \mathrm{mU} / \mathrm{l}$. While numerous clinicians may routinely disregard $\mathrm{SCH}$ in the context of TSH levels $<10$, sufficient evidence exists indicating that these individuals could be exposed to enhanced CV risk, this moreover possibly aggravated by insulin resistance as well as augmented by the co-existence of additional risk factors. ${ }^{54,55}$ Furthermore, recent findings showing that raised serum TSH has a different impact on the lipid profile in morbidly obese compared with non-obese patients indicate that obese patients might not be truly hypothyroid. ${ }^{56}$ Therefore, measurement of TC could be helpful when a decision should be made whether a morbidly obese patient with a raised serum TSH should be treated with levothyroxine treatment or not.

Therefore, until randomised, controlled, prospective and adequately powered trials are carried out, it is advisable to prescribe LT4 therapy on an individualised basis, ${ }^{57}$ taking into account the risk both of progressive thyroid disease and of CV events. Symptomatic patients, those with $\mathrm{CV}$ risk factors, pregnant women, patients with Hashimoto thyroiditis and subjects with ovulatory dysfunction and infertility should as a general rule be treated as their symptoms associated with $\mathrm{SCH}$ can potentially be reversed.

Mild SCH (<10 mu/l) should be scrutinised and carefully followed up so as to preclude progression of disease and promptly initiate treatment. Moderate $\mathrm{SCH}(>10 \mathrm{mu} / \mathrm{l})$ has a negative impact on various $\mathrm{CV}$ risk factors and should be treated in patients $<65$ years. More elderly patients need to be regularly evaluated, while those older than 85 years should probably be followed up, though treatment is largely uncalled for 
1. Klein I, Ojamaa K. Thyroid hormone-targeting the heart, Endocrinology, 2001;142:11-2.

2. Danzi S, Klein I, Thyroid disease and the cardiovascular system, Endocrinol Metab Clin North Am, 2014;43:517-28.

3. McQuade C, Skugor M, Brennan DM, et al., Hypothyroidism and moderate subclinical hypothyroidism are associated with increased all-cause mortality independent of coronary heart disease risk factors: a Precis database study, Thyroid 2011;21:837-43

4. Pearce SHS, Brabant G, Duntas LH, et al., 2013 ETA Guidelines: Management of Subclinical Hypothyroidism, Eur Thyroid J, 2013;2:215-28.

5. Canaris GJ, Manowitz NR, Mayor G, Ridgway EC, The Colorado thyroid disease prevalence study, Arch Intern Med, 2000;160:526-34.

6. Vanderpump MP, Tunbridge WM, French JM, et al., The incidence of thyroid disorders in the community: a twentyyear follow-up of the Whickham Survey, Clin Endocrinol (OXf), 1995;43:55-68.

7. Biondi $B$, Cooper DS, The clinical significance of subclinical thyroid dysfunction, Endocr Rev, 2008;29:76-131.

8. Cappola AR, Fried LP, Arnold AM, et al., Thyroid status, cardiovascular risk, and mortality in older adults, JAMA, 2006;295:1033-41

9. Althaus BU, Staub JJ, Ryff-De Lèche A, et al., LDL/HDL-changes in subclinical hypothyroidism: possible risk factors for coronary heart disease, Clin Endocrinol (Oxf), 1988;28:157-63.

10. Walsh JP, Bremner AP, Bulsara MK, et al., Thyroid dysfunction and serum lipids: a community-based study, Clin Endocrinol (Oxf), 2005;63:670-5.

11. Abrams JJ, Grundy SM, Cholesterol metabolism in hypothyroidism and hyperthyroidism in man, $J$ Lipid Res, 1981;22:323-38

12. Chait $A$, Bierman EL, Albers J, Regulatory role of $T 3$ in the degradation of LDL by cultured human skin fibroblast, I Clin Endocrinol Metab, 1979;48:887-9.

13. Shin DJ, Osborne TF, Thyroid hormone regulation and cholesterol metabolism are connected through stero regulatory element-binding protein-2 (SREBP-2), J Biol Chem, 2003;278:34114-8.

14. Brenta G, Berg G, Zago V, et al., Proatherogenic mechanisms in subclinical hypothyroidism: hepatic lipase activity in relation to the VLDL remnant IDL, Thyroid, 2008;18:1233-6.

15. Valdemarsson $S$, Hansson $P$, Hedner $P$, et al., Relations between thyroid function, hepatic and lipoprotein lipase
activities, and plasma lipoprotein concentrations, Acta activities, and plasma lipoprotein con

16. Bastenie PA, Bonnyns M, Vanhaelst I, Grades of subclinical hypothyroidism in asymptomatic autoimmune thyroiditis revealed by the thyrotropin-releasing hormone test, $J$ Clin Endocrinol Metab, 1980;51:163-6.

17. Staub JJ, Althaus BU, Engler $\mathrm{H}$, et al., Spectrum of subclinica and overt hypothyroidism: effect on thyrotropin, prolactin, and thyroid reserve, and metabolic impact on peripheral target tissues, Am I Med, 1992;92:631-42.

18. Duntas $L H, B$ renta $G$, The effect of thyroid disorders on lipid levels and metabolism, Med Clin North Am. 2012;96:269-81.

19. Iqbal $A$, Jorde $R$, Figenschau $Y$, Serum lipid levels in relation to serum thyroid-stimulating hormone and the effect of thyroxine treatment on serum lipid levels in subjects with subclinical hypothyroidism: the Tromsø Study, I Intern Med, 2006:260:53-61.

20. Hernández-Mijares A, Jover A, et al., Relation between lipoprotein subfractions and TSH levels in the cardiovascular risk among women with subclinical hypothyroidism, Clin Endocrinol (Oxf), 2013;78:777-82.

21. Roos A, Bakker SJ, Links TP, et al., Thyroid function is associated with components of the metabolic syndrome in euthyroid subjects, J Clin Endocrinol Metab, 200;92:491-6.

22. Fabbrini E, Magkos F, Patterson BW, et al., Subclinical hypothyroidism and hyperthyroidism have opposite effects on hepatic very-low-density lipoprotein-triglyceride kinetics, J Clin Endocrinol Metab, 2012;97:E414-8.

23. Ito $\mathrm{M}$, Kitanaka $\mathrm{A}$, Arishima T, et al., Effect of L-thyroxine replacement on apolipoprotein B-48 in overt and subclinical hypothyroid patients, Endocr J, 2013;60:65-71.

24. Meier C, Staub JJ, Roth CB, et al., TSH-controlled L-thyroxine therapy reduces cholesterol levels and clinical symptoms in subclinical hypothyroidism: a double blind, placeboin subclinical hypothyroidism: a double blind, placebo-
controlled trial (Basel Thyroid Study), J Clin Endocrinol Metab, controlled trial (B

25. Psaty BM, Anderson M, Kronmal RA, et al., The association between lipid levels and the risks of incident myocardial infarction, stroke, and total mortality: the Cardiovascular Health Study, J Am Geriatr Soc, 52;1639-47

26. Cooper DS, 2004 Thyroid disease in the oldest old: the exception to the rule, JAMA, 2004;292:2651-4

27. Manuela C, Capalbo D, Wasniewska M, et al., Cardiovascular risk factors in children with long-standing untreated idiopathic subclinical hypothyroidism, J Clin Endocrinol Metab, 2014;99:2697-703.

28. Duan Y, Peng W, Wang $X$, et al., Community-based study of the association of subclinical thyroid dysfunction with blood pressure, Endocrine, 2009:35:136-142.

29. Walsh JP, Bremner AP, Bulsara MK, et al., Subclinical thyroid dysfunction and blood pressure: a community-based study, Clin Endocrinol (Oxf), 2006;65:486-91.

30. Asvold BO, Bjøro T, Vatten L, Associations of TSH levels within the reference range with future blood pressure and lipid concentrations: 11-year follow-up of the HUNT study, Eur Endocrinol, 2013;169:73-82.

31. Cai YF, Shi JP, Meta analysis on the relationship between subclinical hypothyroidism and the levels of systolic blood pressure, Zhonghua Liu Xing Bing Xue Za Zhi, 2011:32:55-9.

32. Owen PJ, Rajiv C, Vinereanu D, et al., Subclinical hypothyroidism, arterial stiffness, and myocardial reserve J Clin Endocrinol Metab, 2006;91:2126-32.

33. Biondi B, Klein I, Hypothyroidism as a risk factor for cardiovascular disease, Endocrine, 2004;24:1-13.

34. Masaki M, Komamura K, Goda A, et al., Elevated arterial stiffness and diastolic dysfunction in subclinica hypothyroidism, Circ J, 2014;78:1494-500.

35. Silva N, Santos OC, Morais FF, et al., Subclinical hypothyroidism represents an additional risk factor for coronary artery calcification, especially in subjects with intermediate and high cardiovascular risk score, Eur J Endocrinol, 2014;171:327-34.

36. Pérez A, Cubero JM, Sucunza N, et al. Emerging cardiovascular risk factors in subclinical hypothyroidism: lack of change after restoration of euthyroidism, Metabolism, 2004;53:1512-5.

37. Duntas $L H$, Biondi B, New insights into subclinical hypothyroidism and cardiovascular risk, Semin Thromb Hemost, 2011;37:27-34.

38. Cantürk Z, Cetinarslan B, Tarkun I, et al., Hemostatic system as a risk factor for cardiovascular disease in women with subclinical hypothyroidism, Thyroid, 2003;13:971-7.

39. Viswanathan G, Balasubramaniam K, Hardy R, et al., Blood thrombogenicity is independently associated with serum
TSH levels in post non ST elevation acute coronary syndrome J Clin Endocrinol Metab, 2014;99(6):E1050-4.

40. Posadas-Romero C, Jorge-Galarza E, Posadas-Sánchez R et al., Fatty liver largely explains associations of subclinical hypothyroidism with insulin resistance, metabolic syndrome, and subclinical coronary atherosclerosis, Eur J Endocrinol, 2014;171:319-25.

41. Garin MC, Arnold AM, Lee JS, et al., Subclinical hypothyroidism, weight change, and body composition in the elderly: the Cardiovascular Health Study, J Clin Endocrino Metab, 2014;99:1220-6.

42. Iervasi G, Molinaro S, Landi P, et al., Association between increased mortality and mild thyroid dysfunction in cardiac patients, Arch Intern Med, 2007:167:1526-32.

43. Ochs N, Auer R, Bauer DC, et al., Meta-analysis: subclinical thyroid dysfunction and the risk for coronary heart disease and mortality, Ann Intern Med, 2008;148:832-45.

44. Walsh JP, Bremner AP, Bulsara MK, et al., Subclinical thyroid dysfunction as a risk factor for cardiovascular disease, ArCh Intern Med, 2005; 165:2467-72.

45. Razvi S, Shakoor A, Vanderpump M, et al., The influence of age on the relationship between subclinical hypothyroidism and ischemic heart disease, I Clin Endocrinol Metab. 2008;93:2998-3007.

46. Singh S, Duggal J, Molnar J, et al., Impact of subclinical thyroid disorders on coronary heart disease, cardiovascular and allcause mortality: a meta-analysis, Int J Cardiol, 2008;28:41-8.

47. Cappola AR, Ladenson PW Hypothyroidism and Atherosclerosis, I Clin Endocrinol Metab, 2003;88:2438-44.

48. Tseng FY, Lin WY, Lin CC, et al. Subclinical hypothyroidism is associated with increased risk for all-cause and cardiovascular mortality in adults, I Am Coll Cardiol, 2012;60:730-7.

49. Zhang $Y$, Chang $Y$, Ryu S, et al., Thyroid hormones and mortality risk in euthyroid individuals: the Kangbuk Samsung Health Study, J Clin Endocrinol Metab, 2014;99:2467-76.

50. Rodondi N, den Elzen WP, Bauer DC, et al., Thyroid Studies Collaboration. Subclinical hypothyroidism and the risk of coronary heart disease and mortality, JAMA, 2010;304:1365-74.

51. Selmer C, Olesen JB, Hansen ML, et al., Subclinical and overt thyroid dysfunction and risk of all-cause mortality and cardiovascular events: A large population study, I Clin Endocrinol Metab, 2014:99:2372-82.

52. Collet TH, Bauer DC, Cappola AR, et al., for the Thyroid Studies Collaboration. Thyroid antibody status, subclinical hypothyroidism, and the risk of coronary heart disease: An hypothyroidism, and the risk of coronary heart disease: An 2014 [Epub ahead of print]

53. Razvi S, Ingoe L, Keeka G, et al., The beneficial effect of L-thyroxine on cardiovascular risk factors, endothelial function, and quality of life in subclinical hypothyroidism randomized, crossover trial, J Clin Endocrinol Metab, 2007;92:1715-23.

54. Duntas $\mathrm{LH}$, Wartofsky L, Cardiovascular risk and subclinical hypothyroidism: focus on lipids and new emerging risk factors. What is the evidence?, Thyroid, 2007;17:1075-84.

55. Mariotti S, Cambuli VM, Cardiovascular risk in elderly hypothyroid patients, Thyroid, 2007;17:1067-73.

56. Rotondi M, Leporati P, Rizza Ml, et al., Raised serum TSH in morbid-obese and non-obese patients: effect on the circulating lipid profile, Endocrine, 2014:45:92-7.

57. Palmieri EA, Fazio S, Lombardi G, Biondi B, Subclinical hypothyroidism and cardiovascular risk: a reason to treat? Treat Endocrinol, Eur J Endocrinol, 2004;3:233-4. 